\title{
Youth, sexuality, and reproduction
}

In contemporary times, youth is considered both the best phase in life and also a period of great risk. The former refers to physical and psychological potential and the latter especially to possible damage to health. Two areas set the stage for such risks: sociability, involving widespread fear of exposure to violence and drug use, and sexuality, with the issues of early sexual initiation, AIDS, and "teenage pregnancy". These concepts, widespread in commonsense and the media, portray youth as incapable of managing their own affective and sexual lives and frequently displaying irresponsible behaviors. The dominant image is one of an unbridled sex life typified by fleeting relationships. This image feeds on a wide variety of prejudices that scientific research should help to deconstruct.

The current thematic issue of Cadernos de Saúde Pública/ Reports in Public Health aims to expand the multidisciplinary collective health perspective, with a peculiarity - it concentrates on a series of studies that have drawn on the database from the GRAVAD Research Project - Teenage Pregnancy: A Multi-center Study on Youth, Sexuality, and Reproduction in Brazil. The project stemmed from the fact that important gaps had been observed in knowledge on a phenomenon that generates intense public debate but has been treated like a self-evident social problem.

Other contributions were incorporated, based on various studies on youth or sexual practices - and how to estimate them - in particular homosexuality.

Adolescent sexuality is one of the spheres for acquiring individual autonomy in relation to the original nuclear family. The construction of this private space presupposes learning about relating affectively and sexually. Modes of sexual interaction derive from cultural prescriptions which vary, according to the historical time, social milieu, and gender. Accumulated knowledge on sexual behaviors, especially since the advent of the HIV/AIDS epidemic, has highlighted the importance of social modeling for sexual conduct and especially the latter's interface with health. Phenomena considered alarming, such as the low rate of contraceptive use among youth and teenage pregnancy merit in-depth study. Abortion is the reverse phenomenon, and is ignored, performed under precarious conditions for poor youth and in protected circumstances for those from higher social strata. Two articles focus specifically on this theme.

In Brazil, STD/AIDS prevention policies have failed to incorporate contraception into their strategies. This separation results from the lack of a broader perspective on the sphere of sexuality and ends up recommending educational and health measures based on individual behavior change. This stance overlooks that behaviors are socially grasped and that important gender differences orient subjects' behavior. It is thus imperative to expand the focus of policies targeting youth.

To approach youth, sexuality, and reproduction through a multidisciplinary prism expands the understanding of the learning processes in sexuality, forms of affective and sexual interaction between partners, prescriptive gender roles, and finally the development of young people's trajectories in relation to health, reproduction, sexuality, and exposure to sexually transmitted diseases.

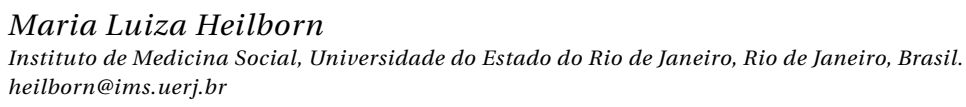

Estela M. L. Aquino

Instituto de Saúde Coletiva, Universidade Federal da Bahia, Salvador, Brasil. estela@ufba.br

Daniela Riva Knauth

Núcleo de Antropologia do Corpo e Saúde, Universidade Federal do Rio Grande do Sul, Porto Alegre, Brasil. knauth@portoweb.com.br 